\title{
Do clinical data and human papilloma virus genotype influence spontaneous regression in grade I cervical intraepithelial neoplasia?
}

\author{
Caterina Cortés-Alaguero1, Esteban González-Mirasol11, José Morales-Roselló², Enrique Poblet-Martinez ${ }^{3}$ \\ 1Department of Obstetrics and Gynecology, Complex Hospital of Albacete University, Albacete, Spain \\ 2Department of Obstetrics and Gynecology, La Fe University and Polytechnic Hospital, Valencia, Spain \\ 3Department of Pathological Anatomy, Reina Sofia General University Hospital, Murcia, Spain
}

\section{Abstract}

Objective: To determine whether medical history, clinical examination and human papilloma virus (HPV) genotype influence spontaneous regression in cervical intraepithelial neoplasia grade I (CIN-I).

Material and Methods: We retrospectively evaluated 232 women who were histologically diagnosed as have CIN-I by means of Kaplan-Meier curves, the pattern of spontaneous regression according to the medical history, clinical examination, and HPV genotype.

Results: Spontaneous regression occurred in most patients and was influenced by the presence of multiple HPV genotypes but not by the HPV genotype itself. In addition, regression frequency was diminished when more than $50 \%$ of the cervix surface was affected or when an abnormal cytology was present at the beginning of follow-up.

Conclusion: The frequency of regression in CIN-I is high, making long-term follow-up and conservative management advisable. Data from clinical examination and HPV genotyping might help to anticipate which lesions will regress. (J Turk Ger Gynecol Assoc 2017; 18: 1-8)

Keywords: Human papilloma virus, cervical intraepithelial neoplasia grade I, human papilloma virus genotyping, regression, low-grade squamous intraepithelial lesion

Received: 6 July, 2016 Accepted: 5 December, 2016

\section{Introduction}

Cervical cancer and its precancerous lesions represent a major health issue, which needs early intervention in order to prevent high morbidity and mortality rates. Extensive research has revealed the existence of a close relationship between the onset of malignant lesions in the female tract and the presence of human papilloma virus (HPV) (1), especially regarding high oncogenic risk genotypes $(2,3)$. The natural history of HPV infection indicates that following an initial HPV infection, a number of patients develop low-grade squamous intraepithelial lesions (LSIL), also known as cervical intraepithelial neoplasia grade I (CIN-I) (4), which occasionally progresses to highgrade squamous intraepithelial lesion $(\operatorname{HSIL})(5,6)$ requiring exhaustive management and follow-up. However, the majority of CIN-I lesions regress without medical intervention, making treatment at this stage superfluous and cost-ineffective (7). Consequently, over-treatment at early stages should be avoided (8), especially in young women, and follow-up periods should be encouraged to make HPV clearance and histologic regression amenable (9).

The ability to identify patients whose lesions regress in advance would help to diminish costs, increase follow-up intervals, and decrease morbidity resulting from invasive diagnosis and unnecessary treatments (10-13). However, the means to anticipate this information are still unavailable. The aim of this study was to determine whether clinical information (medical history and examination) and HPV genotyping were useful to predict the frequency of regression and the need of treatment in CIN-I (14-16). 


\section{Material and Methods}

We retrospectively studied 232 women who were histologically diagnosed as having CIN-I at cervical pathology unit between 1995 and 2007. Most patients were referred for consultation because of an altered cytology. All women's medical histories and clinical examinations including an initial cytology and colposcopy were evaluated. We took a biopsy in the first consultation to make the CIN-I diagnosis. The rest of the followups were done using cytology. The patients were subsequently followed up every 6 months during the first two years, checking for the presence of progression, persistence or regression. When cytology results were normal, annual follow-ups were done for 5 additional years in some cases. CIN-I regression was defined as the disappearance of the lesion without treatment after two consecutive negative follow-ups, considering a negative follow up as both normal cytology and colposcopy, or in cases of altered colposcopy, negative follow up was considered as negative cytology and biopsy. If the cytology follow up resulted in HSIL, the biopsy was repeated. Progression was diagnosed if any change to HSIL was histologically detected. Finally, persistence was considered if no progression or regression was observed during the two-year follow-up. In case of persistence, appropriate treatment was applied.

Unfortunately, being a retrospective analysis, many exceptions applied. These circumstances determined the method of analysis, using Kaplan-Meier curves and excluding contingency tables to avoid comparison biases among the different clinical situations and HPV genotypes. A number of persistent lesions were followed up without treatment for more than 2 years and were seen to regress months afterwards. According to the Kaplan-Meier analysis, these cases were considered "still alive" at the end of the study and were consequently censored data $($ value $=0)$. Some lesions were precipitately treated in the first or second year of follow-up and we therefore disregarded whether they regressed afterwards. According to the KaplanMeier analysis, these cases were considered as cases that "dropped off the study" and were consequently again treated as censored data (value $=0$ ). A third situation was when lesions progressed within the two-year follow-up interval and were treated. We considered them in the same group as those that dropped off the study, and were also classified as censored data (value $=0$ ). The time value in months assigned to these censored data was either the month of treatment or the limit of the study in case of follow-up for more than 2 years. KaplanMeier curves evaluated the pattern of regression using the logrank (Mantel-Cox) test and also provided the median survival and hazard ratio with their $95 \%$ confidence intervals.

Regarding HPV, we evaluated the frequency of the different HPV genotypes $(6,11,16,18,31,33,51$, and 53) and also the different combinations of HPV genotypes (low- and high-risk
HPV, single and multiple HPV). Regression was also evaluated in women with different clinical characteristics including age ( $<25,25-34,35-44,45-54$, and $\geq 55$ years), menopause, age of first intercourse, parity, cigarette smoking, oral contraceptive use, condom use, of intrauterine device (IUD) use, results of the cytologic and colposcopic examination, and cervical extension of colposcopic findings.

Exclusion criteria were: pregnancy, immunodeficiency, existence of concurrent vaginal lesions, follow-up less than two years, lack of data in the patient files, inability to obtain DNA, and treatment immediately after the diagnosis of CIN-I.

HPV genotype was obtained by means of polymerase chain reaction (PCR) according to earlier descriptions using a commercially available kit, SPF10 primers and line probe assay detection system (INNO-LiPA) HPV Genotyping Extra Amp. (Innogenetics, Ghent, Belgium). This system allowed the identification of 9 low-risk HPV genotypes $(6,11,34,40,43,44$, 54, 70, 71), 16 high-risk HPV genotypes (16, 18, 31, 33, 35, 39, 45, $51,52,56,58,59,68,69,73,82)$ and 3 probable high-risk HPV genotypes $(26,53,66)$. The kit also determined additional HPV genotypes (69/71/74) and unclassified HPV genotypes (types $\mathrm{X})$.

The study was undertaken with a protocol authorized by the hospital. Statistics and graphs were constructed using Graph Pad Prism 5.0 (Graph Pad Software, La Jolla, CA, USA). Statistical significance was established at $\mathrm{p}<0.05$.

\section{Results}

A description of the studied population at the onset of follow-up is shown in Table 1. A total of 232 women were included with a mean age of 34.6 years. Of them, 15 (6.5\%) were menopausal, $55(23.7 \%)$ had their first sexual intercourse prior to age 18 years, and $140(60.3 \%)$ had delivered at least once. The most frequent family planning method was the condom, which was used by 88 women (37.9\%), followed by hormonal contraception used by 47 women (20.2\%), surgical methods 30 (12.9), and IUDs 19 (8.2). The majority of patients $(n=218,94 \%)$ were referred due to an abnormal cytology in the absence of any other symptoms, but only 162 (69.8\%) presented with this finding at the onset of follow up. Other patients presented with vaginitis (4.3\%), postmenopausal bleeding (0.4\%) or intercourse bleeding (1.3\%). Nearly all patients had abnormal colposcopy (94.4\%), $68.1 \%$ of which was due to low risk changes. Finally, half of the patients (59.5\%) smoked.

HPV infection was found in 224 patients (96.5\%). Of these, 212 (91.4\%) presented one or several high-risk HPV, 68 (29.3\%) had one or several low-risk HPVs, and 4 (1.7\%) additional or X HPV. Multiple HPV genotypes were found in 125 women (53.9\%) with the following distribution: two different HPV genotypes in 81 women (34.9\%), three in 25 (10.8\%), four in 11 (4.7\%), five in 
Table 1. Clinical description of the population with histologic diagnosis of cervical intraepithelial neoplasia grade I

\begin{tabular}{|c|c|c|}
\hline Clinical data & $\mathbf{n}$ & $\%$ \\
\hline \multicolumn{3}{|l|}{ Age (mean 34.6) } \\
\hline$<25$ & 29 & 12.5 \\
\hline $25-34$ & 91 & 39.2 \\
\hline $35-44$ & 81 & 34.9 \\
\hline $45-54$ & 29 & 12.5 \\
\hline$\geq 55$ & 2 & 0.9 \\
\hline \multicolumn{3}{|l|}{ Menopause } \\
\hline At pre-menopause & 217 & 93.5 \\
\hline Already at menopause & 15 & 6.5 \\
\hline \multicolumn{3}{|l|}{ Onset of sexual intercourse } \\
\hline First intercourse before age 18 years & 55 & 23.7 \\
\hline First intercourse at or after age 18 years & 177 & 76.3 \\
\hline \multicolumn{3}{|l|}{ Parity } \\
\hline No children & 92 & 39.7 \\
\hline At least 1 child & 140 & 60.3 \\
\hline \multicolumn{3}{|l|}{ Smoking } \\
\hline No smoking & 94 & 40.5 \\
\hline Less than 10 cigarettes per day & 67 & 28.9 \\
\hline Between 10-20 cigarettes per day & 55 & 23.7 \\
\hline More than 20 cigarettes per day & 16 & 6.9 \\
\hline \multicolumn{3}{|l|}{ Family planning method } \\
\hline Condom & 88 & 37.9 \\
\hline Oral contraceptives & 47 & 20.2 \\
\hline No family planning methods & 36 & 15.5 \\
\hline Surgical method & 30 & 12.9 \\
\hline IUD & 19 & 8.2 \\
\hline No intercourse & 8 & 3.4 \\
\hline \multicolumn{3}{|l|}{ Presence of clinical symptoms } \\
\hline Absence of symptoms & 218 & 94 \\
\hline Vaginitis & 10 & 4.3 \\
\hline Intercourse bleeding & 3 & 1.3 \\
\hline Postmenopausal bleeding & 1 & 0.4 \\
\hline \multicolumn{3}{|l|}{ Cytology results } \\
\hline Normal cytology & 70 & 30.2 \\
\hline ASCUS & 23 & 9.9 \\
\hline AGUS & 1 & 0.4 \\
\hline Low-risk SIL & 116 & 50.0 \\
\hline High-risk SIL & 22 & 9.5 \\
\hline \multicolumn{3}{|l|}{ Colposcopy results } \\
\hline Normal colposcopy & 13 & 5.6 \\
\hline Metaplasia & 50 & 21.6 \\
\hline ATZ + Low-risk colposcopic changes & 158 & 68.1 \\
\hline ATZ + High-risk colposcopic changes & 11 & 4.7 \\
\hline
\end{tabular}

Table 1. Continued

\begin{tabular}{|c|c|c|}
\hline \multicolumn{3}{|c|}{ Colposcopy image: percentage of cervix affected } \\
\hline Less than $50 \%$ of the cervix surface affected & 171 & 73.7 \\
\hline More than $50 \%$ of the cervix surface affected & 61 & 26.3 \\
\hline \multicolumn{3}{|c|}{$\begin{array}{l}\text { IUD: intrauterine device; ASCUS: atypical squamous cells of undetermined } \\
\text { significance; AGUS: atypical glandular cells of undetermined significance; } \\
\text { SIL: squamous intraepithelial lesion; ATZ: atypical transformation zone. } \\
\text { Cytology and colposcopy were performed in unison in all patients. } \\
\text { Only patients with histologic diagnosis of cervical intraepithelial neoplasia } \\
\text { grade I were included. } \\
\text { In patients with normal colposcopy, an endocervical curettage was } \\
\text { subsequently performed. } \\
\text { In } 171 \text { ( } 73 \%) \text { patients atypical transformation zone extended to less than } \\
50 \% \text { of cervical surface. These included cases where lesion extended into } \\
\text { the cervical channel. }\end{array}$} \\
\hline
\end{tabular}

$6(2.6 \%)$, seven in $1(0.4 \%)$, and eight in $1(0.4 \%)$. Table 2 shows the percentage of infection caused by each virus, isolated or combined with other HPV genotypes. The three most frequent high-risk HPV genotypes were HPV 16, 51, and 53. In 99 (42.7\%) women, the etiology of infection was HPV 16. Of those, 38 (16.4\% of the total number) presented with HPV16 as the only viral genotype. For HPV 51, this occurred in 46 (19.8\%) and 18 (7.7\%) cases, and for HPV 53 in 44 (19\%), and 8 (3.4\%) cases. In 12 women (5.2\%), both HPV 16 and 18 were found. HPV 45 was found in only $2(0.9 \%)$ women and always in association with other viral genotypes. In 99 (42.6\%) women, HPV infection was caused by other high-risk viruses different to HPV 16 and 18. Finally, the most frequent low-risk virus was HPV 11 and less frequently, HPV 6.

Of the 232 CIN-I lesions, 116 regressed in the 2-year follow-up and 9 reached the end of the interval without regression. In addition, 93 were precipitately treated within the two years of follow-up and 14 progressed to HSIL and were treated during the follow-up interval. These last three groups were considered as censored data in Kaplan-Meier analyses.

The analysis of the clinical parameters (Figure 1) showed that the regression frequency was significantly lower only in women who had an abnormal cytology at the onset of followup or who showed colposcopical abnormalities on more than $50 \%$ of the cervical surface. However, there was large influence on regression of characteristics related with sexuality such as condom use and age at first sexual intercourse, but it did not reach significance $(p=0.0565$ and $p=0.0741)$. Influence of other characteristics such as age, colposcopical images (highversus low-risk changes and normal versus abnormal findings), contraceptives use, IUD use, parity, menopause and smoking did not reach statistical significance. Comparison statistics are described in Table 3.

With regards to the HPV genotypes, the analysis showed that regression frequency was significantly influenced only in the presence of multiple combinations of high-risk HPV 
Table 2. Distribution of human papilloma virus infection. n may reflect, isolated or combined human papilloma virus genotypes

\begin{tabular}{|l|l|l|}
\hline HPV infection according to genotype & n & $\%$ \\
\hline \begin{tabular}{|l|l|} 
HPV infection (isolated or combined with similar risk \\
HPV)
\end{tabular} & 232 & 100.0 \\
\hline All HPV genotypes & 212 & 91.4 \\
\hline High-risk HPV & 8 & 3.4 \\
\hline Low-risk HPV & 8 & 3.4 \\
\hline No HPV infection & 4 & 1.7 \\
\hline Additional HPV, HPV X & \multicolumn{2}{|l}{} \\
\hline Most frequent isolated HPV infection & 38 & 16.4 \\
\hline HPV 16 & 18 & 7.7 \\
\hline HPV 51 & 13 & 5.6 \\
\hline HPV 31 & 8 & 3.4 \\
\hline HPV 53 & 6 & 2.6 \\
\hline HPV 33 & 5 & 2.1 \\
\hline HPV 18 & 5 & 2.1 \\
\hline HPV 11 & 2 & 0.9 \\
\hline HPV 6 & \multicolumn{2}{|l}{} \\
\hline
\end{tabular}

High-risk HPV infection (isolated or combined with other High-risk-HPV)

\begin{tabular}{|l|l|l|}
\hline HPV 16 & 99 & 42.7 \\
\hline HPV 51 & 46 & 19.8 \\
\hline HPV 53 & 44 & 19.0 \\
\hline HPV 31 & 32 & 13.8 \\
\hline HPV 18 & 26 & 11.2 \\
\hline HPV 33 & 18 & 7.8 \\
\hline HPV 58 & 17 & 7.3 \\
\hline HPV 52 & 15 & 6.5 \\
\hline HPV 39 & 14 & 6 \\
\hline HPV 66 & 12 & 5.2 \\
\hline HPV 56 & 11 & 4.7 \\
\hline HPV 68 & 11 & 4.7 \\
\hline HPV 35 & 5 & 2.2 \\
\hline HPV 82 & 4 & 1.7 \\
\hline HPV 45 & 2 & 0.9 \\
\hline HPV 26 & 1 & 0.4 \\
\hline LOW-rs & & \\
\hline
\end{tabular}

Low-risk HPV infection (isolated or combined with other Low-risk-HPV)

\begin{tabular}{|l|l|l|}
\hline HPV 11 & 22 & 9.5 \\
\hline HPV 6 & 5 & 2.2 \\
\hline HPV 44 & 4 & 1.7 \\
\hline HPV 54 & 4 & 1.7 \\
\hline HPV 70 & 3 & 1.3 \\
\hline
\end{tabular}

Table 2. Continued

\section{$X$ and additional HPV infection (isolated or combined} with similar HPV)

\begin{tabular}{|l|l|l|}
\hline HPV X (Unknown HPV) & 11 & 4.7 \\
\hline HPV 69/71 & 6 & 2.6 \\
\hline HPV 74 & 2 & 0.9 \\
\hline Specific combination of HPV genotypes & 12 & 5.2 \\
\hline Low risk HPV + additional HPV + HPV X & 87 & 37.5 \\
\hline HPV $16+$ any other HPV & 49 & 21.1 \\
\hline HPV 16 + any other High-risk HPV & 14 & 6.0 \\
\hline HPV $18+$ any other HPV & 9 & 3.9 \\
\hline HPV $18+$ any other High-risk HPV & 12 & 5.2 \\
\hline HPV $16+$ HPV 18 & 99 & 42.7 \\
\hline High-risk HPV different to HPV 16 and HPV 18 & & \\
\hline HPV: human papilloma virus & \multicolumn{2}{l}{} \\
\hline
\end{tabular}

$(p=0.0353)$. Neither the presence of high-risk HPV versus low-risk HPV $(p=0.1717)$ or the different combinations of high-risk HPV $(p=0.4307)$ or the sum of any low-risk plus any high-risk HPV $(p=0.4667)$ were seen to influence regression (Figure 2). Comparison statistics are also described in Table 3. The probabilities of CIN-I regression in relation to each HPV genotype, HPV16/18 or HPV 16/18/31/33/35/51/53/45/52/58 are shown in Table 4.

\section{Discussion}

Our results show that most of the CIN-I lesions disappeared in the two-year follow-up period, which is in line with earlier works quoting similar percentages (17-20). Although HPV is the etiology of cervical cancer and intraepithelial neoplasia, the importance of the different viral genotypes is unclear (21). According to our data, $96.6 \%$ of CIN-I had HPV infection, HPV 16 being the most frequent genotype. This agreed with earlier investigations although with slightly lower percentages $(22,23)$. Also, although HPV 18 was the world's second most frequent HPV genotype (24), it represented only $11.2 \%$ of our cases, a lower frequency than that of HPV 51 (19.8\%), HPV 53 (19\%), and HPV 31 (13.8\%), in line with other works $(25,26)$.

Our results showed that HPV genotype (including HPV 16 and 18) was not a determinant of regression frequency as the survival curves did not show significant differences either in the pattern of regression between HPV 16/18 and the remaining high risk HPV or in the pattern of regression between high and low risk HPV. Concerning earlier references, very few studies examined the influence of the viral type in relation with regression. In addition, previous results were unclear. Some works showed a higher progression to CIN-III for HPV 16 (27), a higher progression to CIN-III and cervical cancer for HPV 16 (28) 
Table 3. Kaplan-Meier statistics for the different parameters analyzed in Figures 1, 2

\begin{tabular}{|c|c|c|c|c|c|c|c|c|}
\hline (Figure number) Parameters analyzed & $\mathbf{n}$ & $\begin{array}{l}\text { n } \\
\text { regression }\end{array}$ & Mean RT & Ratio & 95 CI-R & HzR & 95 CI HzR & p-value \\
\hline (1) Colposcopy: cervical surface affected $>50 \%$ & 61 & 25 & 21 & \multirow{2}{*}{1.7} & \multirow{2}{*}{$1.13-2.37$} & \multirow{2}{*}{0.53} & \multirow{2}{*}{$0.34-0.81$} & \multirow{2}{*}{0.0037} \\
\hline (1) Colposcopy: cervical surface affected $<50 \%$ & 171 & 100 & 12 & & & & & \\
\hline (1) Cytology at the onset of follow-up: abnormal & 162 & 71 & 13 & \multirow{2}{*}{1.3} & \multirow{2}{*}{$0.61-1.99$} & \multirow{2}{*}{0.47} & \multirow{2}{*}{$0.31-0.71$} & \multirow{2}{*}{0.0004} \\
\hline (1) Cytology at the onset of follow-up: normal & 70 & 54 & 10 & & & & & \\
\hline (1) Colposcopy: normal or metaplasia & 63 & 37 & 12 & \multirow{2}{*}{1} & \multirow{2}{*}{$0.33-1.67$} & \multirow{2}{*}{1.31} & \multirow{2}{*}{$0.84-2.03$} & \multirow{2}{*}{0.2356} \\
\hline (1) Colposcopy: low and high-risk changes & 169 & 88 & 12 & & & & & \\
\hline (1) Colposcopy: LR changes & 158 & 85 & 12 & \multirow{2}{*}{0.6} & \multirow{2}{*}{$0.35-0.84$} & \multirow{2}{*}{2.14} & \multirow{2}{*}{$0.87-5.28$} & \multirow{2}{*}{0.0970} \\
\hline (1) Colposcopy: HR changes & 11 & 3 & 20 & & & & & \\
\hline (2) Oral contraception: no & 185 & 99 & 12 & \multirow{2}{*}{1} & \multirow{2}{*}{$0.36-1.64$} & \multirow{2}{*}{1.01} & \multirow{2}{*}{$0.63-1.61$} & \multirow{2}{*}{0.9682} \\
\hline (2) Oral contraception: yes & 47 & 26 & 12 & & & & & \\
\hline (2) Intercourse onset below 18 years old & 55 & 23 & 14 & \multirow{2}{*}{1.17} & \multirow{2}{*}{$0.55-1.78$} & \multirow{2}{*}{0.66} & 042104 & 00741 \\
\hline (2) Intercourse onset at or after 18 years old & 177 & 102 & 12 & & & & $0.4 L-1.07$ & 0.0171 \\
\hline (2) Condom use: no & 146 & 71 & 13 & 12 & 061109 & 067 & 045101 & 0.0565 \\
\hline (2) Condom use: yes & 86 & 54 & 10 & 1.0 & $0.01-1.83$ & 0.0 & $0.40-1.01$ & 0.0500 \\
\hline (2) IUD use: no & 213 & 117 & 12 & 1 & 051149 & 127 & 071266 & 08810 \\
\hline (2) IUD use: yes & 19 & 8 & 12 & 1 & $0.51-1.49$ & 1.31 & $0.11-2.00$ & 0.8010 \\
\hline (3) Pregnancies: no children & 92 & 58 & 11 & 085 & 015154 & 121 & 080104 & 01818 \\
\hline (3) Pregnancies: at least 1 children & 140 & 67 & 13 & 0.85 & $0.15-1.54$ & 1.31 & $0.80-1.94$ & 0.1818 \\
\hline (3) Menopause: yes & 15 & 7 & 14 & 117 & 070163 & 103 & 045234 & 09365 \\
\hline (3) Menopause: no & 217 & 18 & 12 & 1.0 & & & & \\
\hline (3) Smoking: yes & 138 & 73 & 12 & 1 & 031160 & 0.98 & 066145 & 09216 \\
\hline (3) Smoking: no & 94 & 52 & 12 & 1 & $0.01-1.07$ & 0.00 & $0.00-1.40$ & 0.0310 \\
\hline (3) Age: 34 or less & 123 & 66 & 11 & 085 & 015154 & 10 & 075162 & 02500 \\
\hline (3) Age: $>34$ & 109 & 59 & 13 & 0.85 & $0.15-1.54$ & 1.10 & $0.15-1.03$ & 0.2590 \\
\hline (4) High risk HPV & 212 & 112 & 12 & 109 & 052165 & 061 & 1 02012 & 01717 \\
\hline (4) Low risk, X HPV, additional HPV, no HPV & 20 & 13 & 11 & 1.09 & $0.53-1.05$ & 0.01 & $0.30-1.24$ & 0.1718 \\
\hline (4) High risk HPV: 16 and/or 18 & 113 & 58 & 12 & 108 & 040176 & 085 & 056128 & 06209 \\
\hline (4) High risk HPV: other HR HPV & 99 & 54 & 13 & 1.00 & $0.40-1.10$ & 0.05 & $0.50-1.20$ & 0.0209 \\
\hline (4) Multiple HR HPV infection & 125 & 63 & 14 & 100 & 046154 & 126 & 067236 & 05298 \\
\hline (4) Multiple HR, LR, X, and additional HPV & 212 & 119 & 14 & 1.00 & $0.40-1.07$ & 1.20 & $0.01-2.00$ & 0.0200 \\
\hline (4) Single HR HPV & 87 & 49 & 10 & 1.40 & 075205 & 062 & 020097 & 00252 \\
\hline (4) Multiple HR HPV & 125 & 63 & 14 & 1.40 & $0.10-2.03$ & 0.02 & $0.07-0.58$ & 0.0303 \\
\hline
\end{tabular}

or a higher progression to CIN-III for HPV 16, 18, 31, 33, 35, 45, 52 , and 58 (29). Conversely, others showed no increase to CINIII for HPV 16/18 when compared with other high-risk HPV (30). Regarding the combination of different HPV, our analysis showed that the number of high-risk viruses present in the epithelium (single or multiple high-risk HPV infections) influenced the frequency of regression. This was not in line with some previous works (31), but agreed with others that found differences, especially when one of the viruses was HPV $16(32-34)$.
The method by which the sample was obtained (cytology or biopsy) and the PCR method applied are also important issues, because they could influence the number of HPV genotypes detected $(35,36)$. We applied SPF10 primers, genotyping with PCR-SPF10/LiPA. This was an excellent method to detect single and multiple HPV infection in paraffin fixed tissues (37-39), thanks to which we were able to identify HPV in a very high percentage of cases.

In consideration to clinical parameters, it has been suggested that smoking, use of oral contraceptives, sexual behavior, 
parity, and age at first sexual intercourse had an influence on the natural history of HPV intraepithelial lesions. However, most studies dealt with the influence on progression and very few on the influence on regression. Our data, in line with earlier works (27), showed a high influence of the onset of sexual intercourse or the use condom during sexual relationships, which may

Table 4. Probabilities of cervical intraepithelial neoplasia grade I regression in relation to human papilloma virus genotypes

\begin{tabular}{|l|l|l|}
\hline $\begin{array}{l}\text { Human papilloma virus } \\
\text { genotype }\end{array}$ & n patient & Regression \% \\
\hline 6 & 2 & $50 \%$ \\
\hline 11 & 5 & $60 \%$ \\
\hline 16 & 35 & $51 \%$ \\
\hline 18 & 6 & $11 \%$ \\
\hline 31 & 13 & $69 \%$ \\
\hline 33 & 6 & $17 \%$ \\
\hline 51 & 18 & $61 \%$ \\
\hline 53 & 8 & $62 \%$ \\
\hline $16 / 18$ & 113 & $51 \%$ \\
\hline $16 / 18 / 31 / 33 / 35 / 51 / 53 / 45 / 52 / 58$ & 212 & $52.8 \%$ \\
\hline
\end{tabular}
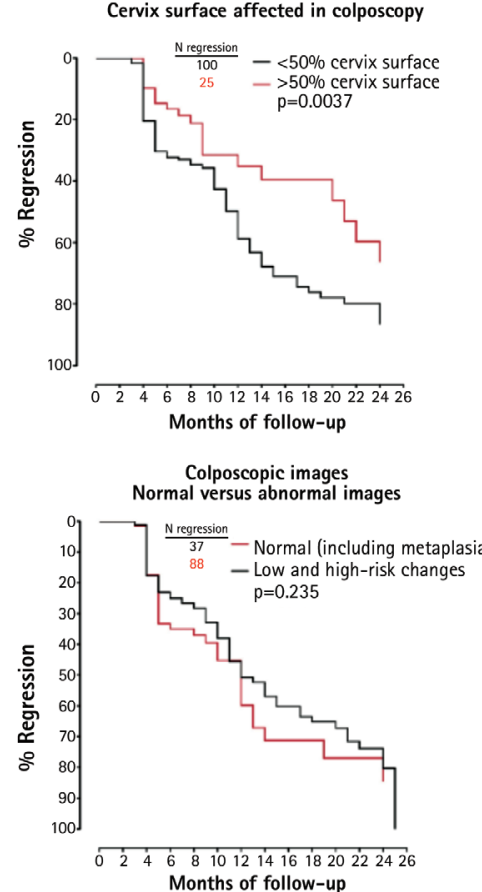

Cytology at the onset of follow-up

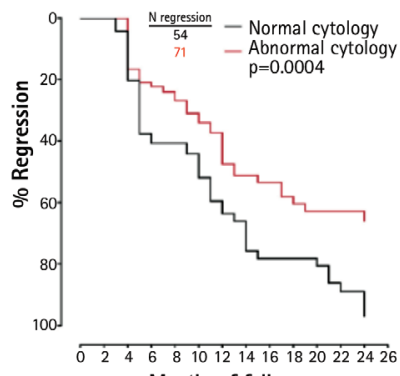
Months of follow-up

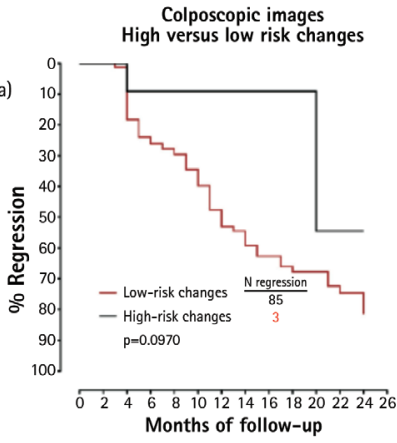

Figure 1. Kaplan-Meier curves evaluating the regression frequency of the cervical intraepithelial neoplasia grade I infections according to the percentage of cervical surface affected, the existence of an abnormal cytology at the onset of follow up, and the presence of different images (normal versus abnormal and high- versus low-risk changes) in the colposcopic examination have yielded significant results with a slightly higher number of patients.

Although colposcopy is an excellent method to investigate abnormal cytologies (40), it cannot substitute histologic evaluation. Our data did not support an influence of colposcopy findings (suggesting lower or higher grade lesions) on the frequency of regression. However, similar to earlier works (41), the presence of a more extended lesion $(>50 \%$ of the cervix surface) indicated that this was less likely to regress. Finally, we showed that regression was less frequent when anomalies were present in the initial cytology. Similar results were obtained in earlier studies, which showed a higher progression to CIN-III in these cases (42).

Finally, several strengths and limitations in the study should be underlined. Concerning the strengths: 1- We used only histologic diagnosis (a biopsy indicating CIN-I) avoiding the high false positive rate of cytology. 2- Our progression reference was CIN-III, avoiding the low correlation among pathologists in CIN-II lesions $(43,44) .3$ - The PCR method applied allowed a wide identification of HPV genotypes and the detection of multiple HPV infections with high sensibility, specificity, and celerity. The number of cases was also low. In addition, many lesions were precipitately treated prior to end of follow up, and
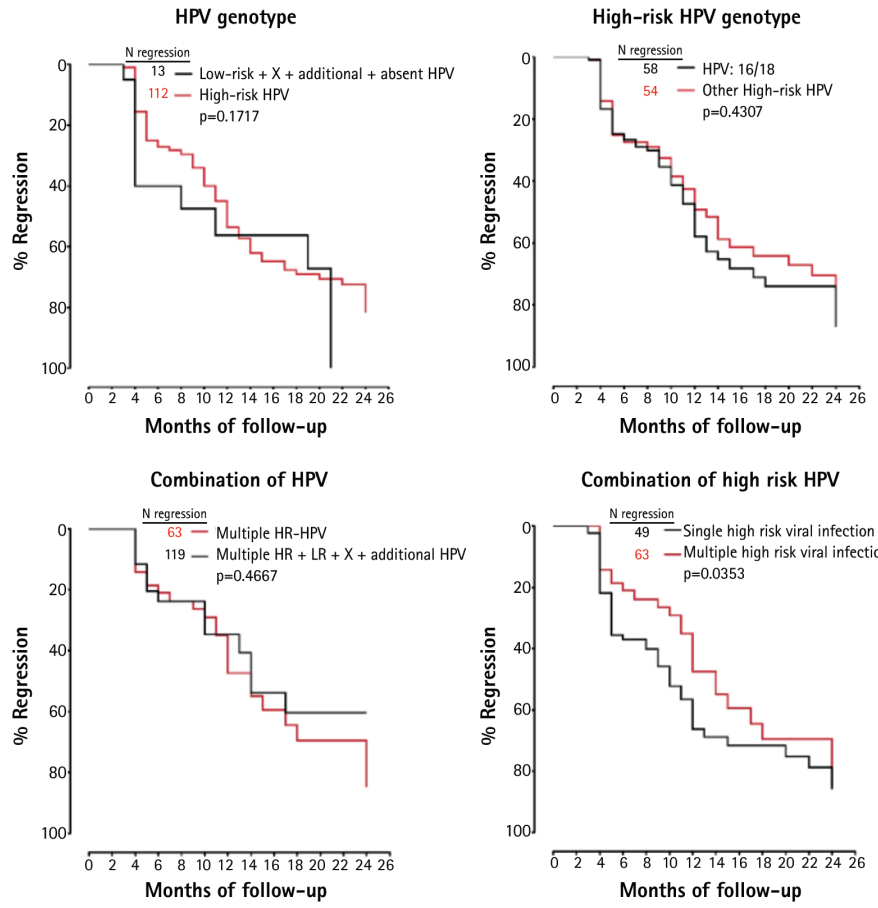

Figure 2. Kaplan-Meier curves evaluating the regression frequency of cervical intraepithelial neoplasia grade I infections according to the human papilloma virus genotype: high-risk versus low-risk, high-risk versus other high-risk, multiple high-risk versus any other multiple and finally single versus multiple high-risk human papilloma virus infection 
therefore, the information of what would have happened if the follow-up had continued was unavailable.

In summary, most CIN-I lesions tend to a spontaneously resolve in the first two years of follow-up. However, the existence of abnormal cytology, an infection in more than $50 \%$ of the cervical surface or the presence of multiple viral high-risk HPV genotypes might influence the frequency of regression making this less likely.

Ethics Committee Approval: Ethics committee approval was received for this study from the ethics committee of Complex Hospital of Albacete University (Number: 06/09, Date: 25.06.2009).

Informed Consent: Oral informed consent was obtained from patients who participated in this study.

Peer-review: Externally peer-reviewed.

Author Contributions: Concept-C.C-A., E.G-M., E.P-M.; Design - C.C-A., E.G-M., E.P-M.; Supervision - C.C-A., E.G-M., J.M-R., E.P-M.; Materials - C.C-A., E.G-M., E.P-M.; Data Collection and/ or Processing - C.C-A; Analysis and/or Interpretation - C.C-A., E.G-M., J.M-R., E.P-M.; Literature Review - C.C-A.; Writer C.C-A., E.G-M., J.M-R.; Critical Review - C.C-A., E.G-M., J.M-R.

Conflict of Interest: No conflict of interest was declared by the authors.

Financial Disclosure: The authors declared that this study has received financial support from FISCAM (Fundación para la investigación sanitaria en Castilla la Mancha).

\section{References}

1. Walboomers JM, Jacobs MV, Manos MM, Bosch FX, Kummer JA, Shah $\mathrm{KV}$, et al. Human papillomavirus is a necessary cause of invasive cervical cancer worldwide. J Pathol 1999; 189: 12-9.

2. Bosch FX, Lorincz A, Muñoz N, Meijer CJ Shah KV. The causal relation between human papillomavirus and cervical cancer. J Clin Pathol 2002; 55: 244-65.

3. Schiffman M, Castle PE, Jeronimo J, Rodriguez AC, Wacholder S. Human papillomavirus and cervical cancer. Lancet 2007; 370: 890-907.

4. IARC monographs on the evaluation of. Human Papillomaviruses/ IARC Working Group on the Evaluation of Carcinogenic Risks to Humans. Lyon, France; 2007.

5. Ostör AG. Natural history of cervical intraepithelial neoplasia: a critical review. Int J Gynecol Pathol 1993; 12: 186-92.

6. Khan MJ, Castle PE, Lorincz AT, Wacholder S, Sherman M, Scott DR, et al. The elevated 10-year risk of cervical precancer and cancer in women with human papillomavirus (HPV) type 16 or 18 and the possible utility of type-specific HPV testing in clinical practice. J Natl Cancer Inst 2005; 97: 1072-9.

7. Ho GY, Bierman R, Beardsley L, Chang CJ, Burk RD. Natural history of cervicovaginal papillomavirus infection in young women. N Engl J Med 1998; 338: 423-8.

8. Insinga RP, Glass AG, Myers ER, Rush BB. Abnormal outcomes following cervical cancer screening: event duration and health utility loss. Med Decis Mak 2007; 27: 414-22.
9. Moscicki AB, Hills N, Shiboski S, Powell K, Jay N, Hanson E, et al. Risks for incident human papillomavirus infection and low-grade squamous intraepithelial lesion development in young females. JAMA 2001; 285: 2995-3002.

10. Koutsky L. Role of epidemiology in defining events that influence transmission and natural history of anogenital papillomavirus infections. J Natl Cancer Inst 1991; 83: 978-9.

11. Nobbenhuis MA, Walboomers JM, Helmerhorst TJ, Rozendaal L, Remmink AJ, Risse EK, et al. Relation of human papillomavirus status to cervical lesions and consequences for cervical-cancer screening: a prospective study. Lancet 1999; 354: 20-5.

12. Koshiol J, Lindsay L, Pimenta JM, Poole C, Jenkins D, Smith JS. Persistent human papillomavirus infection and cervical neoplasia: a systematic review and meta-analysis. Am J Epidemiol 2008; 168: 123-37.

13. Chen HC, Schiffman M, Lin CY, Pan MH, You SL, Chuang LC, et al. Persistence of type-specific human papillomavirus infection and increased long-term risk of cervical cancer. J Natl Cancer Inst 2011; 103: 1387-96

14. Quint WG, Scholte G, van Doorn LJ, Kleter B, Smits PH, Lindeman J. Comparative analysis of human papillomavirus infections in cervical scrapes and biopsy specimens by general SPF(10) PCR and HPV genotyping. J Pathol 2001; 194: 51-8.

15. Melchers WJ, Bakkers JM, Wang J, de Wilde PC, Boonstra H, Quint WG, et al. Short fragment polymerase chain reaction reverse hybridization line probe assay to detect and genotype a broad spectrum of human papillomavirus types. Clinical evaluation and follow-up. Am J Pathol 1999; 155: 1473-8.

16. Holowaty P, Miller AB, Rohan T, To T. Natural history of dysplasia of the uterine cervix. J Natl Cancer Inst 1999; 91: 252-8.

17. Melnikow J, Nuovo J, Willan AR, Chan BK, Howell LP. Natural history of cervical squamous intraepithelial lesions: a metaanalysis. Obstet Gynecol 1998; 92: 727-35.

18. Song SH, Lee JK, Oh MJ, Hur JY, Park YK, Saw HS. Risk factors for the progression or persistence of untreated mild dysplasia of the uterine cervix. Int J Gynecol Cancer 2006; 16: 1608-13.

19. Bansal N, Wright JD, Cohen CJ, Herzog TJ. Natural history of established low grade cervical intraepithelial (CIN 1) lesions. Anticancer Res 2008; 28: 1763-6.

20. Ho GYF, Einstein MH, Romney SL, Kadish AS, Abadi M, Mikhail M, et al. Risk factors for persistent cervical intraepithelial neoplasia grades 1 and 2: managed by waiting. J Low Genit Tract Dis 2011; 15: 268-75

21. Guan P, Howell-Jones R, Li N, Bruni L, de Sanjosé S, Franceschi S, et al. Human papillomavirus types in 115,789 HPV-positive women: a meta-analysis from cervical infection to cancer. Int J Cancer 2012; 131: 2349-59.

22. Sandri MT, Riggio D, Salvatici M, Passerini R, Zorzino L, Boveri S, et al. Typing of human papillomavirus in women with cervical lesions: prevalence and distribution of different genotypes. J Med Virol 2009; 81: 271-7.

23. Mazarico E, Gonzalez-Bosquet E. Prevalence of infection by different genotypes of human papillomavirus in women with cervical pathology. Gynecol Oncol 2012; 125: 181-5.

24. Muñoz N, Bosch FX, de Sanjosé S, Herrero R, Castellsagué X, Shah $\mathrm{KV}$, et al. Epidemiologic classification of human papillomavirus types associated with cervical cancer. N Engl J Med 2003; 348: 518 27.

25. Herrero R, Castle PE, Schiffman M, Bratti MC, Hildesheim A, Morales $\mathrm{J}$, et al. Epidemiologic profile of type-specific human papillomavirus infection and cervical neoplasia in Guanacaste, Costa Rica. J Infect Dis 2005; 191: 1796-807.

26. Ho GY, Kadish AS, Burk RD, Basu J, Palan PR, Mikhail M, et al. HPV 16 and cigarette smoking as risk factors for high-grade cervical intra-epithelial neoplasia. Int J Cancer 1998; 78: 281-5. 
27. Brisson J, Morin C, Fortier M, Roy M, Bouchard C, Leclerc J, et al. Risk factors for cervical intraepithelial neoplasia: differences between low-and high-grade lesions. Am J Epidemiol 1994; 140: 700-10.

28. Rodríguez AC, Schiffman M, Herrero R, Wacholder S, Hildesheim A, Castle PE, et al. Rapid clearance of human papillomavirus and implications for clinical focus on persistent infections. J Natl Cancer Inst 2008; 100: 513-7.

29. Matsumoto K, Oki A, Furuta R, Maeda H, Yasugi T, Takatsuka N, et al. Predicting the progression of cervical precursor lesions by human papillomavirus genotyping: a prospective cohort study. Int $\mathrm{J}$ Cancer 2011; 128: 2898-910.

30. Bello BD, Spinillo A, Alberizzi P, Cesari S, Gardella B, D'Ambrosio G, et al. Cervical infections by multiple human papillomavirus (HPV) genotypes: Prevalence and impact on the risk of precancerous epithelial lesions. J Med Virol 2009; 81: 703-12.

31. Wheeler CM, Hunt WC, Schiffman M, Castle PE; Atypical Squamous Cells of Undetermined Significance/Low-Grade Squamous Intraepithelial Lesions Triage Study Group. Human papillomavirus genotypes and the cumulative 2-year risk of cervical precancer. J Infect Dis 2006; 194: 1291-9.

32. Clifford GM, Rana RK, Franceschi S, Smith JS, Gough G, Pimenta JM. Human papillomavirus genotype distribution in low-grade cervica lesions: comparison by geographic region and with cervical cancer. Cancer Epidemiol Biomarkers Prev. 2005; 14: 1157-64.

33. Trottier H, Mahmud S, Costa MC, Sobrinho JP, Duarte-Franco E, Rohan TE, et al. Human papillomavirus infections with multiple types and risk of cervical neoplasia. Cancer Epidemiol Biomarkers Prev 2006; 15: 1274-80.

34. Campos NG, Rodriguez AC, Castle PE, Herrero R, Hildesheim A Katki H, et al. Persistence of concurrent infections with multiple human papillomavirus types: a population-based cohort study. J Infect Dis 2011; 203: 823-7.

35. Quint WG, Scholte G, van Doorn LJ, Kleter B, Smits PH, Lindeman J. Comparative analysis of human papillomavirus infections in cervical scrapes and biopsy specimens by general SPF(10) PCR and HPV genotyping. J Pathol 2001; 194: 51-8.
36. Castle PE, Porras C, Quint WG, Rodriguez AC, Schiffman M, Gravitt PE, et al. Comparison of two PCR-based human papillomavirus genotyping methods. J Clin Microbiol 2008; 46: 3437-45.

37. Odida M, de Sanjose S, Sandin S, Quiros B, Alemany L, Lloveras $\mathrm{B}$, et al. Comparison of human papillomavirus detection between freshly frozen tissue and paraffin embedded tissue of invasive cervical cancer. Infect Agent Cancer 2010; 5: 15.

38. Perrons C, Kleter B, Jelley R, Jalal H, Quint W, Tedder R. Detection and genotyping of human papillomavirus DNA by SPF10 and MY09/11 primers in cervical cells taken from women attending a colposcopy clinic. J Med Virol 2002; 67: 246-52.

39. Van Hamont D, van Ham MA, Bakkers JM, Massuger LF, Melchers WJ. Evaluation of the SPF10-INNO LiPA human papillomavirus (HPV) genotyping test and the roche linear array HPV genotyping test. J Clin Microbiol 2006; 44: 3122-9.

40. Kyrgiou M, Tsoumpou I, Vrekoussis T, Martin-Hirsch P, Arbyn $\mathrm{M}$, Prendiville $\mathrm{W}$, et al. The up-to-date evidence on colposcopy practice and treatment of cervical intraepithelial neoplasia: the Cochrane colposcopy \& cervical cytopathology collaborative group (C5 group) approach. Cancer Treat Rev 2006; 32: 516-23.

41. Burghardt E, Ostör AG. Site and origin of squamous cervical cancer a histomorphologic study. Obstet Gynecol 1983; 62: 117-27.

42. Castle PE, Gage JC, Wheeler CM, Schiffman M. The clinical meaning of a cervical intraepithelial neoplasia grade 1 biopsy. Obstet Gynecol 2011; 118: 1222-9.

43. Carreon JD, Sherman ME, Guillén D, Solomon D, Herrero R, Jerónimo J, et al. CIN2 is a much less reproducible and less valid diagnosis than CIN3: results from a histological review of population-based cervical samples. Int J Gynecol Pathol 2007; 26: 441-6.

44. Castle PE, Stoler MH, Solomon D, Schiffman M. The relationship of community biopsy-diagnosed cervical intraepithelial neoplasia grade 2 to the quality control pathology-reviewed diagnoses: an ALTS report. Am J Clin Pathol 2007; 127: 805-15. 